\title{
Echocardiographic and anatomical correlations in fetal congenital heart disease
}

\author{
LINDSEY D ALLAN, DIANE C CRAWFORD, ROBERT H ANDERSON, * \\ MICHAEL J TYNAN \\ From Guy's Hospital, London; and the *Cardiothoracic Institute, Brompton Hospital, London
}

SUMMARY In a series of 1600 pregnancies 34 cases of congenital heart disease were correctly identified by fetal echocardiography. In each case echocardiographic diagnosis was confirmed by anatomical study. Termination of pregnancy was done electively in 14 cases: in six because of the identification of a cardiac anomaly and in the remaining eight because of multiple congenital anomalies. The remaining 20 fetuses died subsequently owing either to the complexity of congenital heart disease or to associated extracardiac abnormalities, which were present in more than half the fetuses with congenital heart disease. There were eight errors in interpretation of the fetal echocardiogram. The outcome of the pregnancy was not influenced by the error in any case.

Fetal echocardiography can predict correctly structural malformations of the heart. The technique is sufficiently reliable to give an accurate prognosis in early pregnancy and provide the basis for alterations in obstetric management.

The identification of cardiac structure in the fetus, using cross sectional echocardiography from the sixteenth week of gestation, has now unequivocally been shown to be possible. ${ }^{1-3}$ Also, many and varied congenital cardiac malformations have been shown to be recognisable in intrauterine life..$^{4-6}$ The value of anatomical correlations has been illustrated in the study of the normal fetal heart. Such correlation is of even greater importance in considering the accurate diagnosis of fetal cardiac disease. We therefore report our study of 34 malformations encountered during the examination of 1600 pregnancies.

\section{Subjects and methods}

Using cross sectional echocardiography we examined 1600 mothers to investigate the possibility of predicting congenital heart disease during fetal life. The first 400 subjects were normal pregnancies and provided the basis for understanding fetal cardiac anatomy and for gaining experience of the echocardiographic technique. The subsequent 1200 mothers were referred because the pregnancies were considered to be at increased risk of congenital heart disease. Pregnancies

Requests for reprints to Dr L D Allan, Department of Paediatrics, Guy's Hospital, St Thomas Street, London SE1 9RT.

Accepted for publication 17 July 1984 referred included those with a maternal risk factor present in each pregnancy, such as a family history of congenital heart disease or maternal diabetes, or those pregnancies in which specific factors were detected such as fetal arrhythmia, fetal ascites, extracardiac fetal anomaly, or intrauterine retardation of growth. Maternal exposure to a potential teratogen, such as lithium or rubella, was also a reason for referral.

All the mothers were initially studied by one of us (LDA or DCC) using an Advanced Technical Laboratories Mark III sector scanner. A $5 \mathrm{MHz}$ transducer was usually used, but $3.5 \mathrm{MHz}$ was used when the other failed to give adequate penetration. When abnormalities were suspected the tapes were reviewed by the echocardiographic team. The age of the fetus varied from 16 weeks' gestation to term. Elective studies were done at 18 and 24 weeks, but other pregnancies were examined as and when referred. All mothers underwent two studies whenever possible. Follow up consisted of a clinical examination and echocardiography of the baby at 2 months of age by a paediatric cardiologist. Echocardiography was performed earlier if suggested by clinical findings or if an abnormality was suspected. Cardiac catheterisation and angiography were done if an abnormality was present and surgery contemplated. Patients who were unable to attend for follow up examinations because of the journey required 
(160(10\%)) were examined postnatally by a local paediatrician with special reference to the cardiovascular system. When a fetus or infant died the cardiac specimen was obtained for dissection (by RHA) whenever possible.

\section{Results}

Postnatal follow up confirmed the prediction of a structurally normal heart in 1558 of 1600 pregnancies. Eight errors in prediction occurred, which are discussed below. Abnormalities were correctly predicted in 34 cases. Table 1 shows the range of these defects. Over half were correctly predicted before 24 weeks' gestation. Necropsy confirmed the echocardiographic diagnosis in 32 cases; Figs. 1-5 illustrate this. Fourteen pregnancies were electively terminated. Associated extracardiac abnormality was known to be present before termination in eight cases. Termination was based on the echocardiographic diagnosis alone in six cases. Of these six fetuses, three had associated left atrial isomerism ("polysplenia") at necropsy. There were six intrauterine deaths. Five of the six fetuses that died in utero had developed fetal hydrops before intrauterine death, presumably as a result of the cardiac anomaly. In the fetus with pulmonary atresia there was associated severe intrauterine retardation of growth and maternal diabetes, which may have contributed to intrauterine death. Thirteen affected subjects subsequently died in infancy and one at 2 years of age. Cardiac dissection was performed by RHA in 23 cases and by other pathologists in nine. One child who died suddenly at home aged 2 years and a further infant did not undergo postmortem examination, but the prenatal diagnosis had been confirmed by angiography in the first month of life in both cases.

During the study eight errors occurred in diagnosis. These are listed in Table 2 with the factors that contributed to the error in each case. In seven cases retrospective review of the tapes did not expose the eventual anatomical diagnosis. In most of these the quality of the image was not sufficient to predict normality. In the last case the heart was predicted to be normal, but complete transposition with intact ventricular septum was found postnatally. On reviewing the videotapes in this case the expected postnatal features of complete transposition were seen and the diagnosis was apparent.

Table 1 Cardiac anomalies seen prenatally

\begin{tabular}{|c|c|c|c|c|}
\hline Case No & Diagnosis & $\begin{array}{l}\text { Gestational age at } \\
\text { first presentation } \\
\text { (weeks) }\end{array}$ & $\begin{array}{l}\text { Associated extracardiac } \\
\text { abnormalities }\end{array}$ & Outcome \\
\hline $\begin{array}{r}1 \\
2 \\
3 \\
4 \\
5 \\
6 \\
7 \\
8 \\
9 \\
10 \\
11 \\
12 \\
13 \\
14 \\
15 \\
16 \\
17 \\
18 \\
19 \\
20 \\
21 \\
22 \\
23 \\
24 \\
25 \\
26 \\
27 \\
28 \\
29 \\
30 \\
31 \\
32 \\
33 \\
34\end{array}$ & $\begin{array}{l}\text { Primum atrial septal defect } \\
\text { Hypoplastic aortic arch } \\
\text { Atrioventricular septal defect, aortic atresia } \\
\text { Hypertrophic obstructive cardiomyopathy } \\
\text { Mitral atresia, double outlet right ventricle } \\
\text { Mitral atresia, double outlet right ventricle } \\
\text { Primum atrial septal defect, interrupted aortic arch } \\
\text { Atrioventricular septal defect, pulmonary atresia } \\
\text { Coarctation of aorta } \\
\text { Tricuspid atresia } \\
\text { Hypertrophic obstructive cardiomyopathy } \\
\text { Hypoplastic left heart syndrome } \\
\text { Cardiac rhabdomyoma } \\
\text { Hypoplastic left heart syndrome } \\
\text { Ebstein's anomaly } \\
\text { Hypertrophic obstructive cardiomyopathy } \\
\text { Ventricular septal defect } \\
\text { Hypertrophic obstructive cardiomyopathy } \\
\text { Cardiac tumour } \\
\text { Truncus arteriosus } \\
\text { Ventricular septal defect } \\
\text { Ventricular septal defect, double outlet right ventricle } \\
\text { Aortic atresia } \\
\text { Tetralogy of Fallot } \\
\text { Cardiac tumour } \\
\text { Atrioventricular septal defect } \\
\text { Tetralogy of Fallot } \\
\text { Pulmonary atresia } \\
\text { Tetralogy of Fallot } \\
\text { Tetralogy of Fallot } \\
\text { Aortic stenosis } \\
\text { Hypoplastic left heart } \\
\text { Atrioventricular septal defect, double outlet right ventricle } \\
\text { Double outlet right ventricle, ventricular septal defect }\end{array}$ & $\begin{array}{l}16 \\
18 \\
18 \\
18 \\
19 \\
21 \\
20 \\
21 \\
21 \\
21 \\
22 \\
22 \\
22 \\
23 \\
24 \\
24 \\
24 \\
26 \\
27 \\
27 \\
27 \\
27 \\
32 \\
32 \\
32 \\
33 \\
32 \\
33 \\
33 \\
34 \\
34 \\
34 \\
38 \\
38\end{array}$ & $\begin{array}{l}\text { Trisomy } 21 \\
\text { Turner's syndrome } \\
\text { Hydrocephaly } \\
\text { Renal agenesis } \\
\text { None } \\
\text { Polysplenia } \\
\text { Polysplenia } \\
\text { Polysplenia } \\
\text { None } \\
\text { Ectopia cordis } \\
\text { Meckel's syndrome } \\
\text { None } \\
\text { Tuberous sclerosis } \\
\text { None } \\
\text { None } \\
\text { Renal agenesis } \\
\text { Obstructive uropathy } \\
\text { Obstructive uropathy } \\
\text { None } \\
\text { None } \\
\text { Exomphalos } \\
\text { Intracranial cyst } \\
\text { None } \\
\text { Trisomy } 18 \\
\text { None } \\
\text { None } \\
\text { Exomphalos } \\
\text { None } \\
\text { Hydrocephaly } \\
\text { Trisomy } 18 \\
\text { None } \\
\text { None } \\
\text { Polysplenia } \\
\text { Exomphalos }\end{array}$ & $\begin{array}{l}\text { Termination } \\
\text { Termination } \\
\text { Termination } \\
\text { Termination } \\
\text { Termination } \\
\text { Neonatal death } \\
\text { Termination } \\
\text { Termination } \\
\text { Neonatal death } \\
\text { Termination } \\
\text { Termination } \\
\text { Termination } \\
\text { Termination } \\
\text { Intrauterine death } \\
\text { Intrauterine death } \\
\text { Termination } \\
\text { Neonatal death } \\
\text { Termination } \\
\text { Intrauterine death } \\
\text { Death at } 4 \text { months } \\
\text { Neonatal death } \\
\text { Termination } \\
\text { Neonatal death } \\
\text { Neonatal death } \\
\text { Intrauterine death } \\
\text { Intrauterine death } \\
\text { Death at } 6 \text { months } \\
\text { Intrauterine death } \\
\text { Neonatal death } \\
\text { Neonatal death } \\
\text { Neonatal death } \\
\text { Neonatal death } \\
\text { Death at } 2 \text { years } \\
\text { Neonatal death }\end{array}$ \\
\hline
\end{tabular}



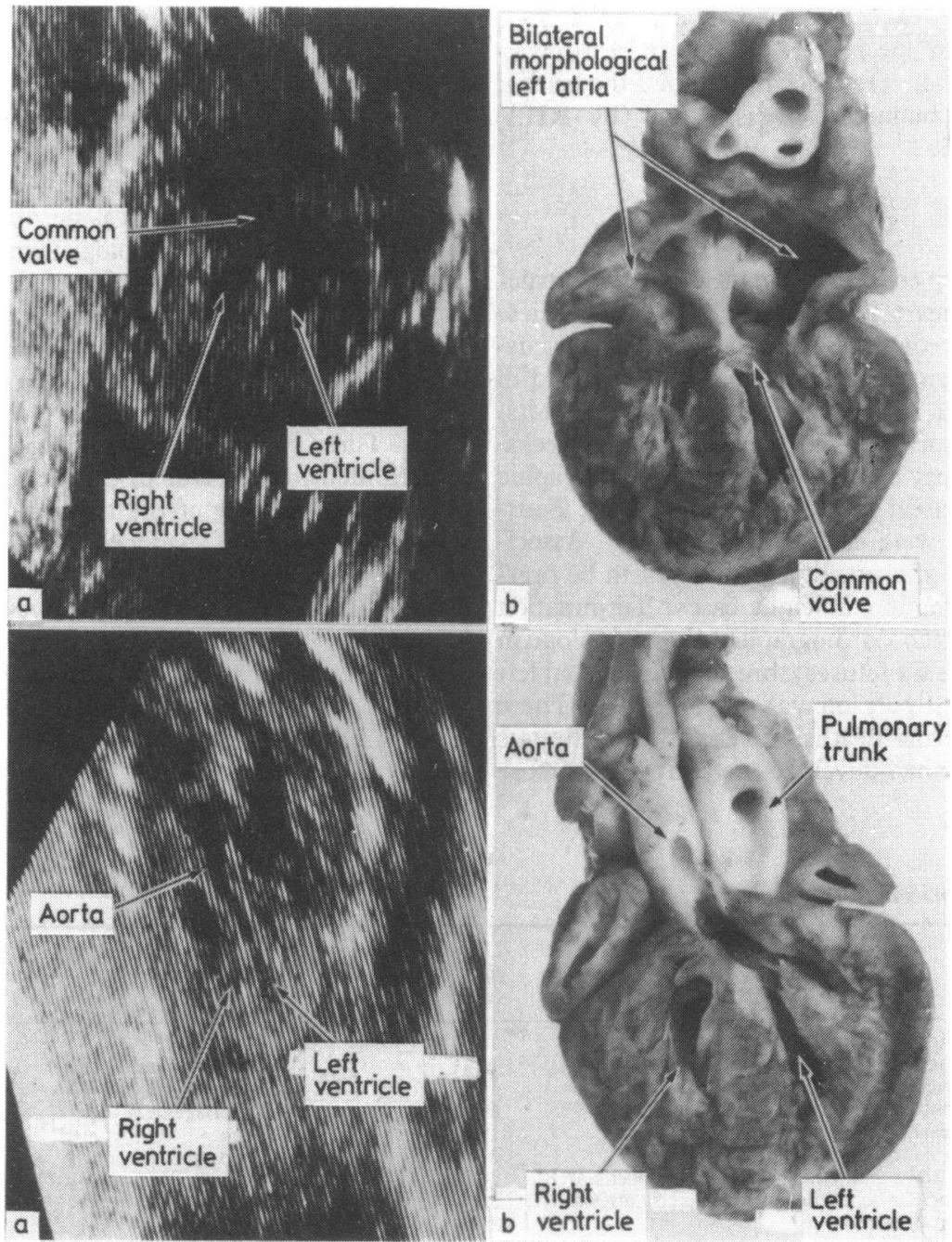

Fig. 1 (Top) Echocardiogram (a) and postmortem dissection (b) both showing the origin of the aorta from the left ventricle and head and neck vessels arising from the interrupted segment of the ascending aorta. (Bottom) Echocardiogram and dissection from the same patient showing an ostium atrioventricular defect. The insertion of the two atrioventricular valves is seen to be at the same level on the ventricular septum (Case 7.)

\section{Discussion}

The observed incidence of congenital heart disease in this series (one in 40) shows that this was a selected group of pregnancies. If the initial $\mathbf{4 0 0}$ normal pregnancies are not included, no cardiac abnormalities having been found in this group, the incidence in the high risk pregnancies studied was one in 30. Furthermore, the series is not representative of congenital heart disease as a whole, as evidenced by the high mortality. That none of the fetuses of the con- $N$ tinued pregnancies survived longer than two years of $N$ age was in part due to the complexity and severity of the cardiac anomalies and in part to the association of other malformations. These were present in $21(62 \%) \stackrel{\varrho}{\circ}$ of our cases of cardiac anomaly. Six fetuses, however, with isolated congenital heart disease died in utero. Two of these had obstructive cardiac tumours but the ${ }^{\circ}$ four others (with Ebstein's anomaly, pulmonary $\mathbb{\mathbb { D }}$ atresia, the hypoplastic left heart syndrome, and $\underset{\mathbb{D}}{\stackrel{?}{*}}$ 


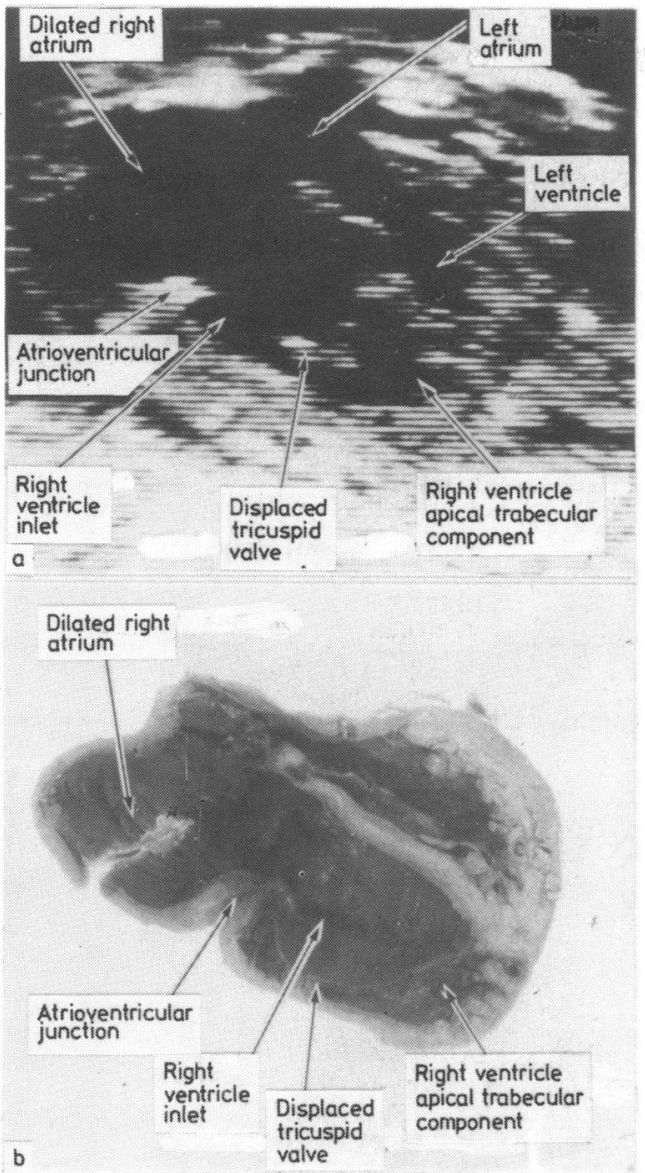

Fig. 2 Echocardiogram (a) and postmortem dissection (b) of heart of same fetus (case 15) in four chamber plane showing the displacement of the tricuspid valve and dilatation of the right atrium, typical of Ebstein's anomaly. atrioventricular septal defect, respectively) were perhaps surprising.

In general, the echocardiographic criteria for diagnosing individual defects were the same in utero as in postnatal life. Thus fetuses with atrioventricular septal defect presented the typical common atrioventricular junction (Fig. 1). The fetus with Ebstein's malformation showed the apical displacement of the septal leaflet of the tricuspid valve together with gross dilatation of the right atrium (Fig. 2). The fetuses with hypertrophic cardiomyopathy identified in utero were indistinguishable from those seen postnatally, and histology confirmed the presence of abundant myocardial disarray. In none of the three cases of hypertrophic cardiomyopathy was there maternal diabetes or a family history. All three had been referred because of the identification of renal abnormalities in the fetus.

Differences between prenatal and postnatal criteria were, however, noted in some cases; for example, in the four fetuses with tetralogy of Fallot the ventricles were of similar thickness, and subpulmonary stenosis was not apparent in early pregnancy. The diagnosis was initially made on the basis of the aortic override, and the condition differentiated from single outlet of the heart by the identification of a pulmonary artery and pulmonary valve. The infundibular stenosis had become evident in all cases by the end of pregnancy. Also in the case of coarctation of the aorta, when first seen at 21 weeks' gestation, there was simply right ventricular hypertrophy with a suspicion of a discrete coarctation but without isthmal hypoplasia. The isthmal narrowing did not develop until after 30 weeks of pregnancy.

The errors in diagnosis should be looked at in the context of the accurate prediction of a normally connected heart in nearly 1600 pregnancies. The errors

Table 2 Errors in echocardiographic diagnosis

\begin{tabular}{|c|c|c|}
\hline Diagnosis & Associated features & Factors possibly contributing to error \\
\hline \multicolumn{3}{|l|}{ False positive prediction: } \\
\hline Ostium primum atrial septal defect & Duodenal atresia & $\begin{array}{l}\text { Hydramnios in late pregnancy (33 weeks' } \\
\text { gestation), one examination }\end{array}$ \\
\hline Ventricular septal defect & Down's syndrome & $\begin{array}{l}\text { One examination, early pregnancy (18 weeks' } \\
\text { gestation) }\end{array}$ \\
\hline \multicolumn{3}{|l|}{ Mistaken prediction: } \\
\hline $\begin{array}{l}\text { Aortic stenosis predicted; ventricular } \\
\text { septal defect found }\end{array}$ & $\begin{array}{l}\text { Right ventricle dilatation, small } \\
\text { aortic root }\end{array}$ & One examination, late pregnancy ( 34 weeks' gestation) \\
\hline \multicolumn{3}{|l|}{ False negative prediction: } \\
\hline $\begin{array}{l}\text { Primum atrial septal defect } \\
\text { Perimembranous ventricular septal defect }\end{array}$ & $\begin{array}{l}\text { Down's syndrome } \\
\text { None }\end{array}$ & $\begin{array}{l}\text { Defect } 2 \mathrm{~mm} \text { in size at necropsy, one examination } \\
\text { Defect } 3-4 \mathrm{~mm} \text { in size on echocardiogram at delivery, } \\
\text { maternal obesity }\end{array}$ \\
\hline Tetralogy of Fallot & Down's syndrome & $\begin{array}{l}\text { One examination, maternal obesity, } \\
\text { oligohydramnios, ventricular septal defect less than } \\
3 \mathrm{~mm} \text { in size }\end{array}$ \\
\hline $\begin{array}{l}\text { Transposition of the great arteries, } \\
\text { ventricular septal defect, interrupted } \\
\text { aortic arch }\end{array}$ & Trisomy 18 & $\begin{array}{l}\text { Late pregnancy ( } 38 \text { weeks' gestation), } \\
\text { oligohydramnios }\end{array}$ \\
\hline Transposition of the great arteries & Gross malformation of other twin & One examination \\
\hline
\end{tabular}



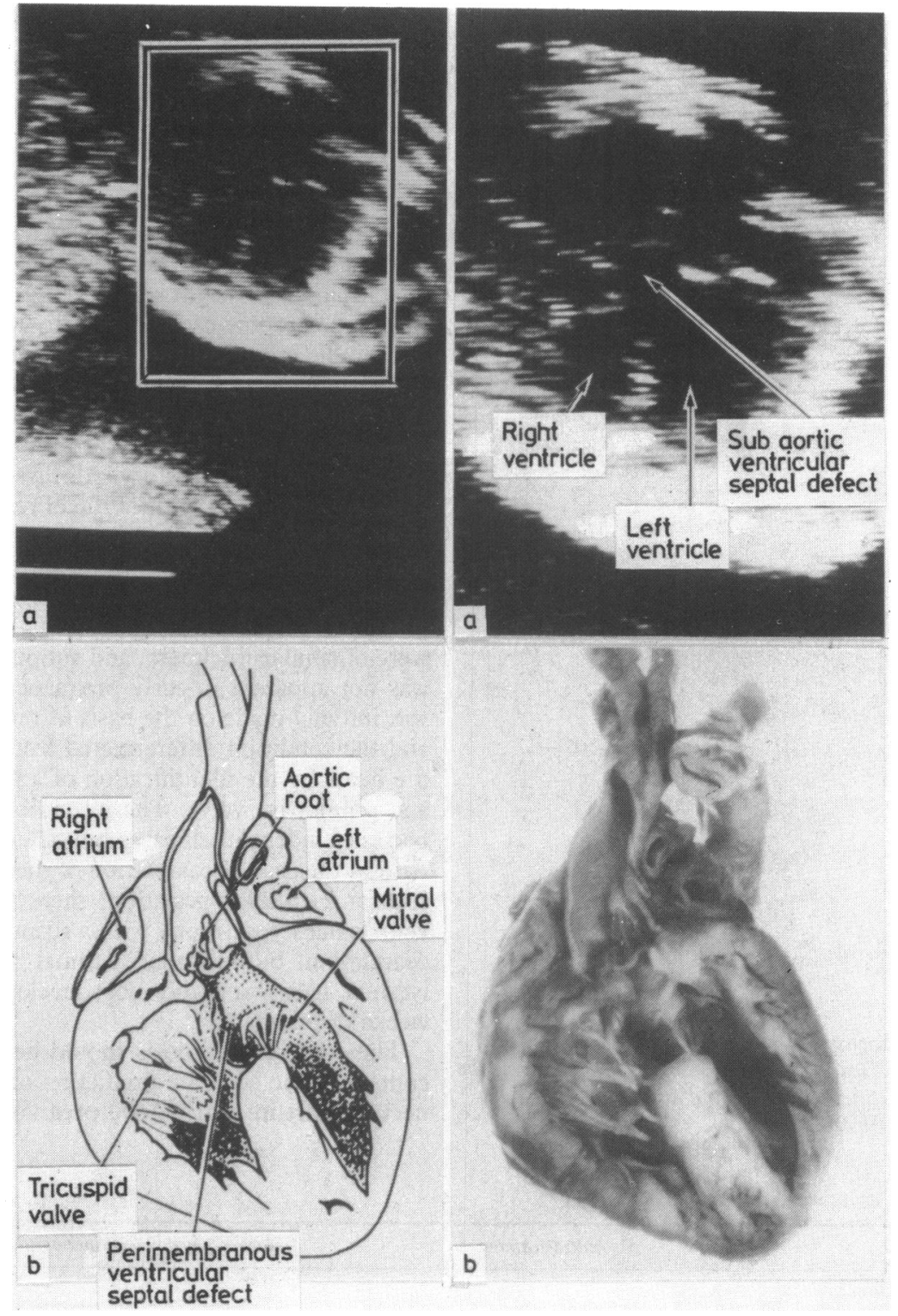

Fig. 3 Echocardiograms (and enlargement) (a) and postmortem dissections (b) showing a large perimembranous inlet septal ventricular defect. (Case 21.)

described illustrate some of the difficulties of echocardiographic examination that are peculiar to the fetal study. For example, maternal obesity, oligohydramnios, polyhydramnios, or late gestational age will all limit the quality of the image and make interpretation difficult. The errors, however, also illustrate limitations of the echocardiographic technique shared by both the fetal and the postnatal study.
This is exemplified by the failure to identify small septal defects, as those of $\leqslant 2-3 \mathrm{~mm}$ in diameter are below the limits of resolution of our equipment.

Each error in diagnosis led to review of the technique to prevent its repetition. For example, after the case of complete transposition had been overlooked, no subsequent study was accepted as ruling out an abnormality until the aortic arch had been identified 


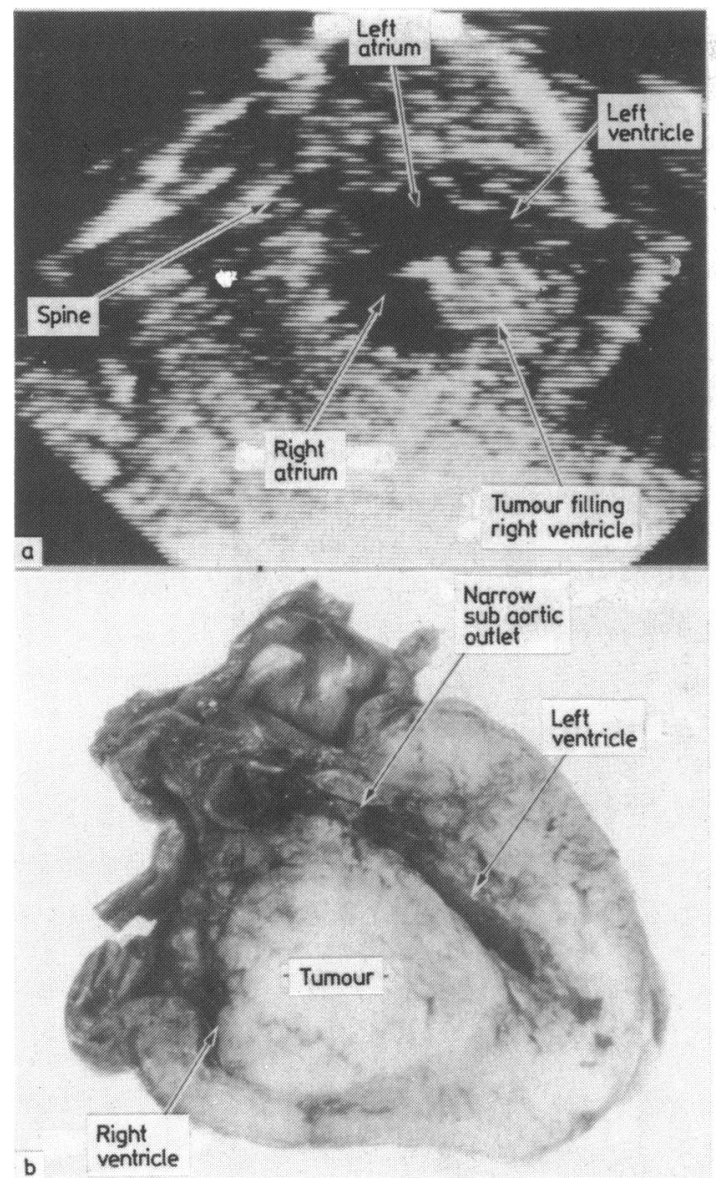

Fig. 4 Echocardiogram (a) taken in four chamber plane and postmortem dissection (b) showing a cardiac tumour filling the right ventricle and obstructing the tricuspid valve. The anatomical section shows the left ventricular outfow tract partially obstructed by the septal displacement. (Case 13.)

and the "crossing over" of the two great arteries seen. After the false prediction of a ventricular septal defect, this diagnosis was not made unless the defect was seen in two planes of section. Factors contributing to many of the errors were poor quality of the image and only one opportunity for examination. Having noted this, we did not make predictions later in our experience unless the quality of the image was adequate or a second examination was possible. We generally achieve good quality of the image in over $95 \%$ of cases so it is only in a few cases that the combination of poor image quality and a single opportunity for study occurs. With the exception of those related to the resolution capacity of current machinery, we think that errors could have been avoided and we adhered to strict rules of methodology. These rules are the positive identification of all the venous, intracardiac, and ventricular arterial connexions, with scrutiny of the ventricular septum from multiple planes of section in every case. With experience of the technique, this is possible between 16 weeks' gestation and term, although most difficult in the last eight weeks of pregnancy.

Accurate diagnosis of cardiac abnormality in fetal life is of extreme importance as decisions about management are made on echocardiographic criteria alone. In postnatal life clinical information and corroborative investigations are available. Increasing reliance, however, is now being placed on echocardiograms postnatally. Decisions regarding clinical management for non-intervention or for surgical treatment are made without invasive investigation. ${ }^{78}$ This series shows that, in a paediatric cardiac centre, the fetal echocardiographic technique can become sufficiently reliable to form the basis for firm recommendations on clinical management. The options for management include termination of pregnancy or continuing pregnancy with or without altered obstetric management. Decisions concerning termination of pregnancy are irrevocable, and there must therefore be complete confidence in the accuracy of the anatomical diagnosis. Once a diagnosis has been made the parents are given the fullest possible understanding of the defect by the echocardiographic team. This allows the parents to make their own decision concerning continuation of the pregnancy in consultation with their obstetrician. Psychological support, whatever the decision made, is an essential part of any form of prenatal diagnosis. Obstetric management may be influenced by the finding of a combination of congenital abnormalities; this might, for example, suggest that an operative delivery should be avoided or provide a stronger indication for the recommendation of termination of pregnancy. The value of modification of place or method of delivery has yet to be determined, but when a malformation is predicted we would recommend that patients be delivered in a hospital with a paediatric cardiac centre.

In conclusion, this study illustrates the learning curve we have experienced with the fetal echocardiographic technique. It shows that complex cardiac malformations may be correctly analysed. The accuracy of the differentiation of abnormality from normality is sufficient for decisions about management to be made. Errors may be minimised by experience and strict adherence to details of technique.

RHA is supported by the Joseph Levy Foundation and the British Heart Foundation. LDA and DCC are supported by the British Heart Foundation. 

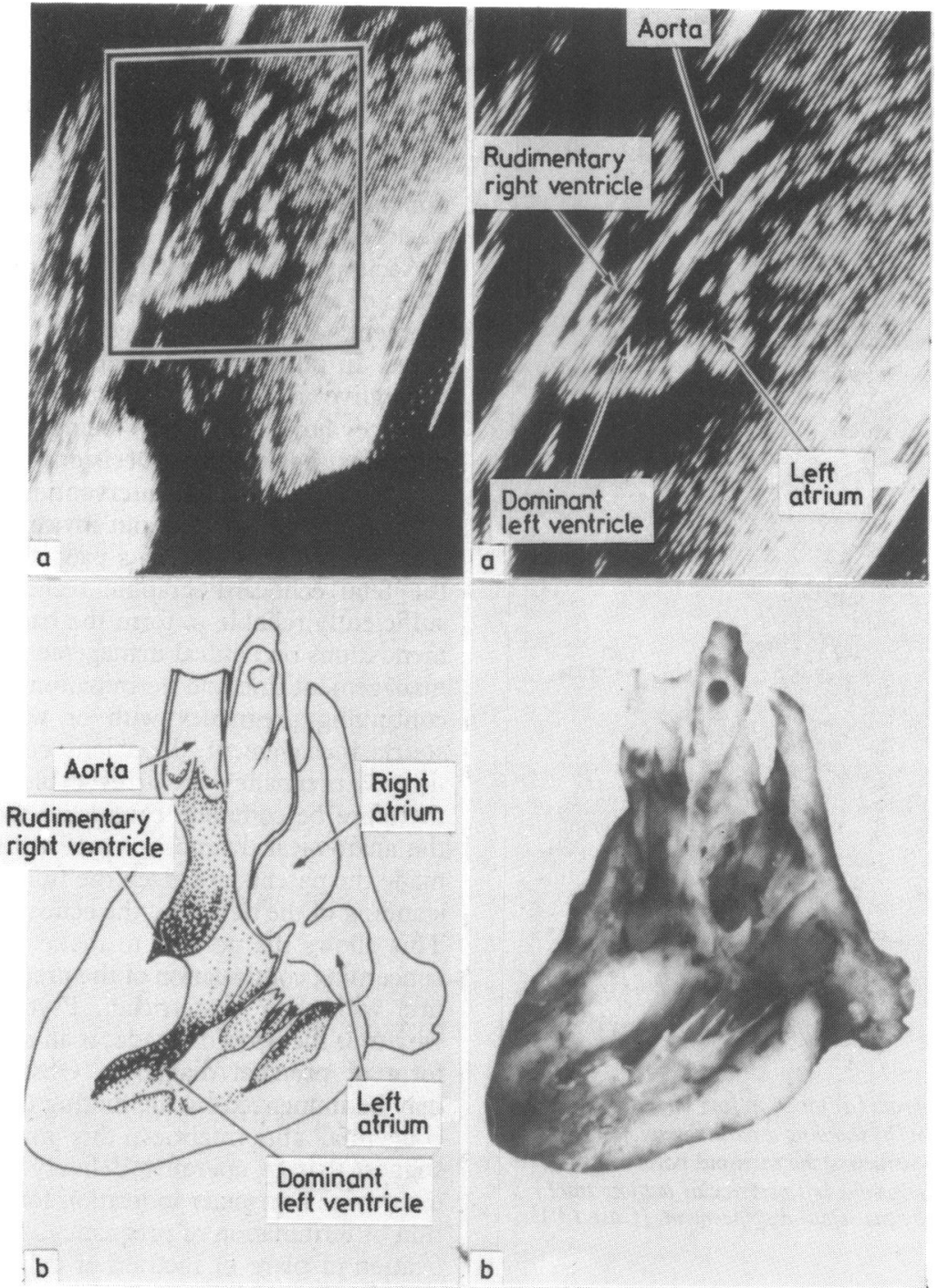

Fig. 5 Echocardiograms (and enlargement) (a) and postmortem dissections (b) showing the aorta arising astride a small rudimentary right ventricle that communicates with the dominant left ventricle via a ventricular septal defect. (Case 10.)

\section{References}

1 Kleinman CS, Hobbins JC, Jaffe CC, Lynch DC, Talner NS. Echocardiographic studies of the human fetus: prenatal diagnosis of congenital heart disease and cardiac dysrhythmias. Pediatrics 1980; 65: 1059-67.

2 Sahn DJ, Lange LW, Allen HD, et al. Quantitative real-time cross-sectional echocardiography in the developing normal human fetus and newborn. Circulation 1982; 62: 588-97.

3 Allan LD, Tynan MJ, Campbell S, Wilkinson JL, Anderson RH. Echocardiographic and anatomical correlates in the fetus. $\mathrm{Br}$ Heant f 1980; 44: 444-51.

4 Kleinman CS, Donnerstein RL, Devore GR, et al. Fetal echocardiography for evaluation of in utero congestive heart failure. $N$
Engl f Med 1982; 306: 568-75.

5 Allan LD, Tynan M, Campbell S, Anderson RH. Normal fetal cardiac anatomy $\rightarrow$ a basis for the echocardiographic detection of abnormalities. Prenat Diagn 1981; 1: 131-9.

6 Allan LD, Tynan M, Campbell S, Anderson RH. Identification of congenital cardiac malformations by echocardiography in midtrimester fetus. Br Heart f 1981; 46: 358-62.

7 Stark J, Smallhorn J, Huhta J, et al. Surgery for congenital heart defects diagnosed with cross-sectional echocardiography. Circulation 1983; 68 (suppl II): 129-38.

8 Rice MJ, Seward JB, Hagler DJ, et al. Impact of 2-dimensional echocardiography on the management of distressed newborns in whom cardiac disease is suspected. Am $\mathcal{f}$ Cardiol 1983; 51 : 28892. 